\title{
Primary rhegmatogenous retinal detachment: 20 years of change
}

\author{
Miriam Minihan, Vaughn Tanner, Tom H Williamson
}

\begin{abstract}
Aim-To compare characteristics, management, and outcome of two groups of patients with primary rhegmatogenous retinal detachment (RRD) presenting to the same vitreoretinal unit approximately 20 years apart.

Methods-124 patients in 1979-80 and 126 cases in 1999 were compared.

Results-More cases were pseudophakic and fewer aphakic in 1999 than 1979-80. More cases of giant retinal tear and fewer dialyses were operated on in 1999. Vitrectomy was a primary procedure in $63 \%$ of cases in 1999 but only $1 \%$ in 1979-80. Anatomical success rates were statistically similar: $79.8 \%$ primary and $88.8 \%$ final success in $1979-80$, and $84 \%$ primary and $93.6 \%$ final success in 1999 .

Conclusion-Surgical management of primary RRD has changed greatly in 20 years. Success rates have changed little, despite availability of differing surgical techniques.

(Br F Ophthalmol 2001;85:546-548)
\end{abstract}

Repair of primary rhegmatogenous retinal detachment (RRD) was usually unsuccessful before Gonin ${ }^{1}$ demonstrated the importance of localising and sealing retinal breaks. Scleral buckling introduced by Custodis, ${ }^{2}{ }^{3}$ intraocular gases by Norton, ${ }^{4}$ and development of vitreous surgery by Machemer ${ }^{5}$ profoundly changed the history of RRD repair. Pars plana vitrectomy (PPV), a method originally reserved for complicated cases, is now used increasingly for primary repair of uncomplicated RRD. ${ }^{6}$ With these changes and others, ${ }^{8-10}$ ever more difficult cases of RRD are now operated upon.

We studied two groups of patients with primary RRD operated upon at the same institution approximately 20 years apart, to examine whether presenting characteristics have changed and to determine differences in our surgical approach and success rates.

Vitreoretinal Unit, Department of Ophthalmology, St Thomas's Hospital, Lambeth Palace Road, London SE1 7EH, UK $M$ Minihan

V Tanner

T H Williamson

Correspondence to: Miss M Minihan miriamm@freeuk.com

Accepted for publication 17 January 2001 Methods repair of primary RRD in St Thomas's Hospital during 1999 and in 1979 and 1980 from the vitreoretinal database. The annual number of cases of primary RRD presenting to this institution has virtually doubled in the 20 years, therefore we chose to analyse the 2 years 1979 and 1980 to provide a similar number of cases to the 1999 period. We compared patient characteristics, cause of RRD, refractive error, lens status, and presence of preoperative proliferative vitreoretinopathy (PVR). We examined the surgical approach undertaken and the anatomical and visual outcome in the two groups. Results were analysed using $\chi^{2}$ analysis and Student's $t$ test.

\section{Results}

There were 124 cases of primary RRD in 123 patients treated in the 1979-80 period, and 126 in 1999. There was no difference in the presenting age, sex, side, or refractive error involved.

In 1979-80, $91(73.4 \%)$ patients presented with macula off RRD. There were significantly fewer, $69(55 \%)$, in $1999(p=0.002)$. There was a greater number of aphakic RRDs $(13.7 \%)$ in $1979-80$ than in $1999(0.8 \%)$ $(\mathrm{p}<0.001)$, and a greater number of pseudophakic RRDs in 1999 (24\%) than in 1979-80 when there was only $1(0.8 \%)(p<0.001)$.

There was no difference between RRDs due to single or multiple breaks but in 1979-80 more were due to dialysis, 19 versus eight $(p=0.007)$, and fewer due to giant retinal tear, none versus nine $(p=0.02)$. In $1979-80$ the presence of PVR was noted but not graded using the classification in use by us today. ${ }^{11}$ In 1979-80 32, and in 199924 had preoperative PVR, and in 199924 patients had PVR, which was not significantly different.

SURGERY (FIG 1)

In $1979-80,82(66 \%)$ cases had non-drain procedures, consisting of cryotherapy to the retinal break and external plombage with a silicone explant (external plomb/non-drain), 41 (33\%) had conventional procedures with external drainage of subretinal fluid (external plomb/drain), and one had PPV. In 1999, 41 (32\%) cases were external plomb/non-drain procedures, five $(5 \%)$ were external plomb/ drain procedures and $79(63 \%)$ were PPVs. Seventeen cases underwent encirclement procedure in 1979-80 whereas in 1999 none did $(p=0.00007)$. In 1999, $32(25 \%)$ cases had PPV with silicone oil tamponade as a primary procedure, 23 of whom had preoperative PVR, and nine had RRD associated with giant retinal tear.

In $1979-80,99(79.8 \%)$ of 124 cases were successfully reattached with one procedure; 14 cases underwent one further procedure, and three underwent two further procedures. Final anatomical success rate was $88.7 \%$ (110 of 124). In 1999 the primary success rate was 106 $(84 \%)$ cases of 126 . Ten cases underwent one further procedure and two had two further procedures. Final success rate was 93.6\% (118 of 126). There was no significant difference in the primary $(p=0.37)$ or final success rates $(p=0.08)$ between the two groups. 

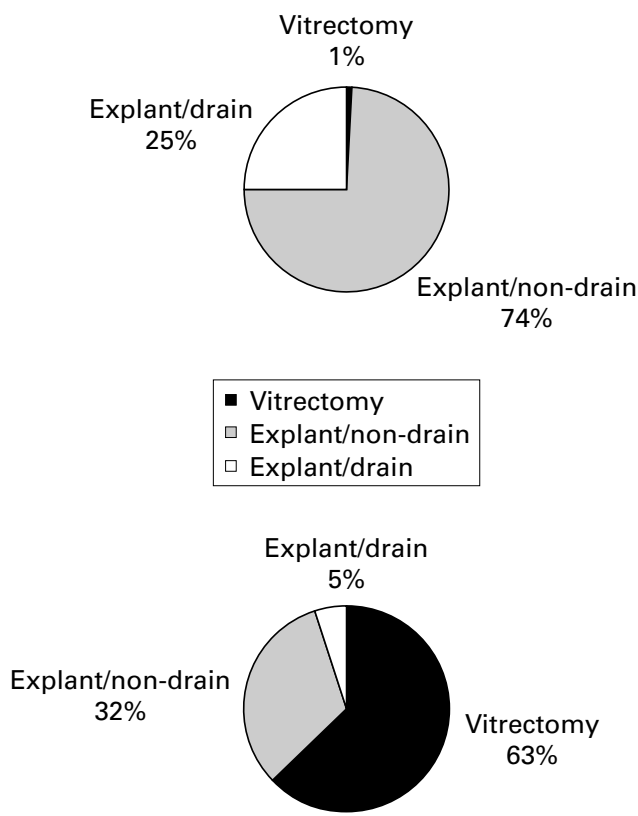

Figure 1 Surgical methods. Top, 1979-80; bottom 1999.

Of the 33 pseudophakic cases in 1999, five $(15 \%)$ had external plomb/non-drain procedures, and $28(85 \%)$ vitrectomy. There was an $85 \%$ primary success rate.

Median preoperative visual acuity in 1979-80 and 1999 was counting fingers. Median postoperative visual acuity was $6 / 24$ in 1979-80 and in 1999. In 1979-80 31\% of cases had a final visual acuity of $6 / 12$ or better, while $47 \%$ did in 1999 . Visual acuity results were statistically similar.

Complications were encountered in both groups in small numbers. There were significantly more intraoperative unplanned SRF drainages in 1979-80, 11 versus three $(p=0.004)$ and more postoperative cataracts in 1999,18 versus five $(\mathrm{p}=0.005)$.

\section{Discussion}

In the 20 years that separate our two groups of patients, much has changed in the management of primary RRD. This study is limited because the patients are not directly comparablemethods of assessment, referral practice, and workload have changed. We only compare patients operated upon and not those who presented. Nevertheless, the study allowed us to examine some of those changes, to reappraise results, and to reflect on future developments.

Primary anatomical success was $79.8 \%$ in $1979-80$ and $84 \%$ in 1999 . The final success rate was $88.7 \%$ in $1979-80$ and $93.6 \%$ in 1999. The success rates of both groups compare with currently available figures. Sullivan et $a l^{12}$ reported a primary success rate of $80 \%$ in a prospective audit of retinal detachment surgery. The pneumatic retinopexy study group $^{13}$ reported a primary success rate of $84 \%$ in their scleral buckling group and $62 \%$ in the pneumatic retinopexy group. Ah-Fat et al examined the trends in vitreoretinal surgery over a 10 year period in their unit. They found a primary anatomical success rate of $76.6 \%$ in 1987 and $84.7 \%$ in 1997 . Their final success rate was $89.1 \%$ in 1987 and $94.3 \%$ in 1997 . A trial of PPV without scleral buckle for pseudophakic retinal detachments reported by Campo et $a l^{14}$ achieved an $88 \%$ primary and $96 \%$ final success rate.

Despite our success rates being similar to those in the literature it is, none the less, disappointing that these figures have not significantly improved in 20 years. We are dealing with significantly fewer dialysis detachments, a type of RRD with a high success rate, and more cases associated with giant retinal tear, a more complex form of RRD. ${ }^{15}$ We cannot say whether any such cases were encountered in the 1979-80 period, and did not undergo surgery, as we do not know what cases, if any, were excluded.

Pseudophakic RRDs accounted for nearly a quarter of patients presenting with primary RRD in 1999. These cases can pose a problem in that capsule changes and the intraocular lens itself can preclude an adequate view of the posterior pole. Vitrectomy overcomes much of this difficulty and indeed our rate of vitrectomy, at $85 \%$, was higher in this subgroup than in the group as a whole. In 1979-80 14\% of presenting cases were aphakic, fundus view, and break detection can also be difficult in such cases. ${ }^{16}$

The most striking difference in the comparison of the two cohorts of patients was surgical technique. In 1979-80, one case of primary RRD was treated with vitrectomy, now $63 \%$ of our cases are managed in this way. The large percentage of vitrectomies reflects a growing trend to manage RRDs in this way. ${ }^{6} 10$

The most common complication of vitrectomy is nuclear sclerotic cataract ${ }^{17}$ and we encountered significantly greater numbers in 1999. The only other significant difference in complication rate was a greater incidence of unplanned SRF drain in 1979-80, reflecting the higher proportion of conventional procedures undertaken.

The overall visual results are similar in each group reflecting the anatomical results.

We have shown a marked difference in current management of primary RRD compared with 20 years ago and outlined the changes in clinical presentation of the patient operated upon. A lack of significant improvement in success rates indicates that further progress must be sought by finding and treating more retinal breaks ${ }^{12}$ and preventing PVR. ${ }^{18}$

The authors would like to thank Mr A H Chignell for his permission to examine his patients' records.

1 Gonin J. Le Decollement de la retine. Pathogenie-traitment. Lausanne: Libraire Payot 1934.

2 Custodis E. Bedeutet die plombenaufnahung auf die sklera einen fortschritt in der operatven behandlung der netzhautablosung. Ber Dtsch Ophthalmol Ges 1953;58:102.

3 Lincoff HA, Baras I, McLean J. Modifications to the Custodis procedure for retinal detachment. Arch Ophthamlol 1965;73:160.

4 Norton EW. Intraocular gas in the management of selected retinal detachments. Trans Am Acad Ophthalmol 1973;77: $85-98$.

5 Machemer R, Buettner H, Norton EWD, et al. Vitrectomy: a pars plana approach. Tans Am Acad Ophthalmol Otolaryngol $1971 ; 75: 813$

6 Gartry DS, Chignell AH, Franks WA, et al. Pars plana vitrectomy for the treatment of rhegmatogenous retinal detachments uncomplicated by advanced proliferative vitreoretinopathy. Br F Ophthalmol 1993;77:199-203. 
7 Af-Fat FG, Sharma MC, Majid MA, et al. Trends in vitreoretinal surgery at a tertiary referral centre: 1987 to 1996. Br f Ophthalmol 1999;83:396-8.

8 Cibis PA, Becker B, Canaan S. The use of silicone oil in retinal detachment surgery. Arch Ophthalmol 1962;68:590. 9 Scott JD. Treatment of the detached immobile retina. Tran Ophthalmol Soc UK 1972;92:351.

10 Chang S. Low viscosity liquid fluorochemicals in vitreous surgery Am f Ophthalmol 1987;103:38.

11 Retina Society Terminology Committee. The classification of retinal detachment with proliferative vitreoretinopathy. Ophthalmology 1983;90:121-5.

12 Sullivan PM, Luff AJ, Aylward GW. Results of primary retinal reattachment surgery: a prospective audit. Eye 1997;11: 869-71.

13 Han DP, Mohsin NC, Guse CE, et al. Comparison of pneumatic retinopexy and scleral buckling in the management of primary rhegmatogenous retinal detachment. Southern Wisconsin Pneumatic Retinopexy Group. Am $\mathcal{F}$ Ophthalmol 1998;126:658-68.

14 Campo RV, Sipperley JO, Sneed SR, et al. Pars plana vitrectomy without scleral buckle for pseudophakic retinal detachments. Ophthalmology 1999;106:1811-5.

15 Chang S, Lincoff H, Zimmerman NJ, et al. Giant retinal tears: surgical techniques and results using perflourocarbon liquids. Arch Ophthalmol 1989;107:761-6.

16 Chignell AH, Fison LG, Davies G, et al. Failure in retinal detachment surgery. Brf Ophthalmol 1973;57:525-30.

17 De Bustros S, Thopson JT, Michels RG, et al. Nuclear sclerosis after vitrectomy for idiopath

18 Kon CE, Asaria RHY, Occleston NL, et al. Risk factors for proliferative vitreoretinopathy: a prospective study. $\mathrm{Br} \mathcal{F}$ Ophthalmol 2000;84:506-11. 